\title{
Caveolin-I: a multifaceted driver of breast cancer progression and its application in clinical treatment
}

This article was published in the following Dove Medical Press journal:

OncoTargets and Therapy

\author{
Xian-Ling Qian ${ }^{1,2}$ \\ Yi-Hang Pan ${ }^{1,2}$ \\ Qi-Yuan Huangl,3 \\ Yu-Bo Shi' \\ Qing-Yun Huang' \\ Zhen-Zhen $\mathrm{Hu}^{1,4}$ \\ Li-Xia Xiong ${ }^{1,4}$
}

'Department of Pathophysiology, Basic Medical College, Nanchang University, Nanchang 330006, China; ${ }^{2}$ First Clinical Medical College, Nanchang University, Nanchang 330006, China; ${ }^{3}$ Second Clinical Medical College, Nanchang University, Nanchang 330006, China; ${ }^{4}$ Jiangxi Province Key Laboratory of Tumor Pathogenesis and Molecular Pathology, Nanchang 330006, China
Correspondence: Zhen-Zhen Hu; Li-Xia Xiong

Department of Pathophysiology, Basic Medical College, Nanchang University, No. 46I Bayi Road, Nanchang, Jiangxi Province 330006, China

Tel +86079186360562

Fax +86079186360556

Email huzhenzhen@ncu.edu.cn; xionglixia@ncu.edu.cn

\begin{abstract}
Human breast cancer is one of the most frequent cancer diseases and causes of death among female population worldwide. It appears at a high incidence and has a high malignancy, mortality, recurrence rate and poor prognosis. Caveolin-1 (Cav1) is the main component of caveolae and participates in various biological events. More and more experimental studies have shown that Cav1 plays a critical role in the progression of breast cancer including cell proliferation, apoptosis, autophagy, invasion, migration and breast cancer metastasis. Besides, Cav1 has been found to be involved in chemotherapeutics and radiotherapy resistance, which are still the principal problems encountered in clinical breast cancer treatment. In addition, stromal Cav1 may be a potential indicator for breast cancer patients' prognosis. In the current review, we cover the state-of-the-art study, development and progress on Cav1 and breast cancer, altogether describing the role of Cav1 in breast cancer progression and application in clinical treatment, in the hope of providing a basis for further research and promoting CAV1 gene as a potential target to diagnose and treat aggressive breast cancers.
\end{abstract}

Keywords: breast cancer, caveolin-1, migration, metastasis, prognosis, invasion

\section{Introduction}

Breast cancer is a common malignant disease among female population worldwide and is characterized by the highest cancer incidence, high recurrence rate, morbidity, mortality and poor prognosis. ${ }^{1-4}$ Breast cancer tumorigenesis is a multi-step process including proliferation, apoptosis, autophagy, invasion, migration, metastasis and drug resistance. According to pathological characteristics, human breast cancer can be divided into non-invasive breast cancer (eg, Paget disease of the breast), ${ }^{5}$ invasive breast carcinoma of special type (eg, invasive apocrine carcinoma, invasive micropapillary carcinoma), ${ }^{6,7}$ invasive breast carcinoma of no special type (eg, invasive lobular carcinoma, invasive ductal carcinoma), ${ }^{8-10}$ inflammatory breast cancer (IBC) and so on. Among them, invasive breast carcinoma of no special type is the most common type and IBC patients often show a poor prognosis. According to molecular type [estrogen receptor (ER), progesterone receptor (PR) and human epidermal growth factor receptor-2 (HER-2)], human breast cancer is divided into luminal A (ER+, PR+, HER-2-), luminal B (ER+, PR+, HER-2+), normal breast-like, HER-2 over-expressing, and basal-like breast cancer. ${ }^{11}$ Triple-negative breast cancer (TNBC) is a subtype of basallike breast cancer that is characterized by the absence of expression of ER, PR and HER2. ${ }^{12-14}$ With high proliferative capacity and recurrence rate, poor differentiation with large tumor size and lack of recognized biomarker, TNBC is a clinical challenge 
for targeted therapy. ${ }^{15-17}$ Canine mammary tumor (CMT) is considered a suitable model for human breast cancer, owing to it showing a similar tumor microenvironment (TME), carcinogens and cancer risk factors. ${ }^{18,19}$ Cancer-associated fibroblasts (CAFs) play a key role in cancer initiation and progression. ${ }^{20}$ Although significant advances in surgery, chemotherapy and radiotherapy have greatly improved the prognosis of breast cancer patients, ${ }^{21}$ breast cancer still remains one of the most common causes of female death. Therefore, it is necessary to summarize the latest molecular mechanisms related to breast cancer progression.

Caveolae are 50-100 $\mathrm{nm} \Omega$-shaped, ${ }^{22,23}$ cholesterolenriched, rigid membrane microdomains that are composed of scaffold proteins named caveolins, including caveolin-1, caveolin-2 and caveolin-3 (Figure 1); caveolin-1 and caveolin-2 are expressed in all human tissues, while caveolin-3 is expressed in muscles. ${ }^{24-28}$ Caveolin-1 (Cav1) is a $21-22 \mathrm{kDa}$ integral membrane protein and the coding gene of CAV1 is located in the D7S522 locus in the q31.1 region of human chromosome 7 and consists of three exons. ${ }^{29}$ Further, Cav1 can participate in various events including endocytosis, signal transduction, membrane trafficking, cholesterol homeostasis, lipid transport and storage, cell cycle, proliferation, apoptosis, cancer cell invasion, migration and metastasis. ${ }^{30-38}$ In normal mammary parenchymal cells' carcinogenic process, Cav1 can act both as tumor suppressor and promoter depending on the subtypes and stages of cancers. ${ }^{39-41}$ In addition, recent studies have shown that caveolae integrity is associated with cancer cell survival, apoptosis and migration and metastasis $;{ }^{42-45}$ so we consider Cav1 in caveolae may play a necessary role in the breast cancer development.

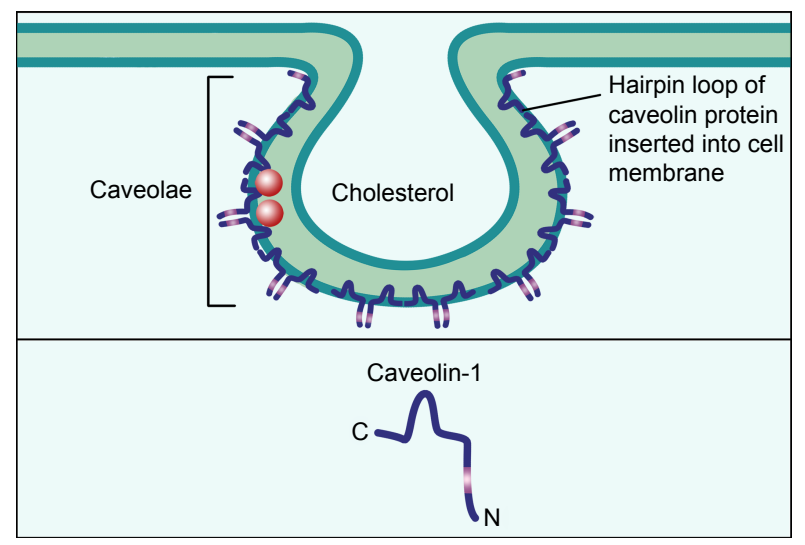

Figure I The structure of caveolae.

Notes: Caveolae are 50-100 nm $\Omega$-shaped, cholesterol-enriched, rigid membrane microdomains that are composed of scaffold proteins named caveolins. The most important constituent protein is Caveolin-I.
In order to define the interaction between Cav1 and breast cancer, in this review, we cover the state-of-the-art study, development and progress on Cav1 and breast cancer, altogether describing the role of Cav1 in breast cancer progression, including cell proliferation, apoptosis, autophagy, invasion, migration and breast cancer metastasis. Moreover, the application of Cav1 in breast cancer clinical treatment is also clarified, such as chemotherapeutics resistance, radiotherapy resistance and diagnosis, in the hope of promoting the clinical application of Cav1.

\section{CavI and breast cancer cell proliferation}

Cav1-induced changes in the expression and activation of ion channels and receptors on the cell membrane may play an important role in breast cancer cell proliferation. Cav1 can act as a tumor suppressor in MCF-7 cells, the downregulation of Cav1 can promote the proliferation by increasing membrane expression and function of large conductance $\mathrm{Ca}^{2+}$-activated potassium (BKCa) channel whose encoding gene contributes to malignancy, thus accelerating the process of carcinogenesis. ${ }^{46}$ Contrarily, parenchymal Cav1 can also act as a tumor promoter by promoting EGFR binding to the kinase domain of caveolin-binding motif, thereby potentially activating EGFR-mediated mitosis initiation. ${ }^{47}$ HER2 overexpression and excessive HER2 signaling were observed in $25 \%$ of breast cancer patients with poor prognosis; $;{ }^{48}$ so Alawin et al allowed $\gamma$-tocotrienol to accumulate within the caveolae microdomain, which lead to caveolae disruption, subsequent interference with HER2 dimerization in caveolae microdomain, phosphorylation (activation) and mitogenic signaling transduction in SKBR3 and BT474 human breast cancer cells. ${ }^{49}$

Cav1 can decrease G0/G1 phase cell cycle arrest and increase the $\mathrm{S}$ phase cell number by activating the extracellular signal-regulated kinase (ERK) 1/2 pathway and increasing the expression of cell cycle-associated proteins (cyclin D1 and $\beta$-catenin) in BT474 cells. ${ }^{50}$ On the contrary, Cav1 acts as an antiproliferative factor in MDA-MB-231 and MCF-7 cells through promoting cell cycle arrest in the G2/M phase, which was accomplished by upregulation of p21, p27 and cyclin B1 and downregulation of cyclin D2, and this antiproliferative effect was enhanced with the cooperation of docetaxel (DTX). ${ }^{51}$ The completely opposite effect of Cav1 on cell proliferation may be due to the difference of used cell lines in two experiments, and more importantly, breast cancer cells were treated with DTX in Kang et al's study.

The malignant features of cancer cells can not only affect tumor development but also the interaction between neoplastic cells and the TME can act as a significant factor in 
the process of breast cancer progression, ${ }^{52}$ and Cav1 plays a multifunctional role in this process. High oxidative stress is usually observed in the stroma of human breast cancers and it can induce stromal catabolism, ${ }^{53}$ stromal Cav1 transportation from cancer-associated stroma to breast cancer cells is low and this leads to a proliferative effect. ${ }^{54}$ Bisphenol A (BPA) is commonly used as an analog of estrogen to mimic estrogenic effects, ${ }^{55-57} \mathrm{Xu}$ et al found that under a hypoxic TME, BPA in MDA-MB-231 cells could trigger G-protein estrogen receptor competitive binding to Cav1, leading to the release of heat shock protein 90 to stabilize and activate hypoxia inducible factor-1 alpha, which upregulated the expression of vascular endothelial growth factor (VEGF), thus inducing proliferative effects. ${ }^{52,58}$ In addition to a hypoxic TME, the effect of CAFs is another factor which influences the occurrence and progression of breast cancers. Reduced expression levels of Cav1 mRNA and Cav1 in CAFs trigger the expression and secretion of stromal cell-derived factor-1, EGF and fibroblast-specific protein-1 (FSP-1), and all of them can accelerate breast cancer cell proliferation rate. ${ }^{59}$

As mentioned above, we demonstrate that Cav1 can affect breast cancer cell proliferation rate by 1) influencing the expression and activation of ion channels and receptors on the cell membrane, such as BKCa channel, EGFR and HER2; 2) regulating cell cycle arrest and affecting mitosis process and 3) mediating the interaction between the TME (hypoxia conditions and CAFs) and breast cancer cells.

\section{Cavl and breast cancer cell autophagy and apoptosis}

Apoptosis is a complex biological process with the formation of apoptotic bodies and morphological and biochemical changes in the nucleus, ${ }^{60,61}$ and both the intrinsic and extrinsic apoptotic pathways are typically inhibited in cancer cells through overexpression of antiapoptotic proteins and underexpression of proapoptotic proteins. ${ }^{62}$ Autophagy is a process known to degrade intracellular proteins and organelles by forming various membrane structures, including autophagosomes, lysosomes and autolysosomes. ${ }^{63}$ Novel types of selective autophagy have been identified, including mitophagy, pexophagy, lipophagy, ERphagy and nucleophagy, all of them facilitate the removal of damaged cellular compartments and recycle components, thereby preventing cells from apoptosis and increasing survivability. ${ }^{64}$

Cav1 can regulate intrinsic and extrinsic apoptotic pathway proteins, thus affecting the process of breast cancer cell apoptosis. Owing to lipid rafts being enriched with cholesterol, methyl beta cyclodextrin $(\mathrm{M} \beta \mathrm{CD})$ as a choles- terol depleting agent can induce lipid raft disruption and mediate MDA-MB-231 and 468 cells apoptosis by downregulating the mRNA and protein expression level of Cav1 and Wnt receptor LRP6, and they can synergistically affect expression of apoptosis-related protein, such as survivin, Bcl-2, Bax and caspase- $3 .{ }^{65}$ On the contrary, with the DTX treatment, elevated mRNA and protein expression level of Cav1 in TNBC cells induces Bcl-2 phosphorylation (inactivation) and expression of $\mathrm{p} 53$, Bax and cleaved poly-ADPribose polymerase, thus exposing MCF-7 and MDA-MB-231 cells to the apoptotic process. ${ }^{51}$

Cav1-induced autophagy alternation can influence cell apoptosis. An enhanced expression level of autophagyrelated proteins (Beclin-1, light chain 3-II and Atg12/5) in BT474 cells is realized by $17 \beta$-estradiol (E2)-induced Cav1 upregulation, resulting in the formation of autophagosome and inhibition of apoptosis. ${ }^{66}$ Shi et al found that Cav1 deficiency and lipid raft disruption could elevate autophagy levels and inhibit apoptosis by promoting V-ATPase assembly, which could activate lysosomal function and autophagosome-lysosome fusion. ${ }^{67}$

Chemotherapeutic drugs can regulate transcriptional level of $C A V 1$, thus promoting apoptosis of breast cancer cells. Salis et al found that fluvastatin induced cytotoxic effects on MCF-7 cells through a reduction of the mRNA expression levels of $C A V 1$ and serum and glucocorticoid-regulated kinase $1(S G K 1),{ }^{68}$ conversely, they also found metformininduced cytotoxic effect on MCF-7 cells was realized by an enhanced mRNA expression of $C A V 1$ while a reduction of $S G K 1,{ }^{69}$ and the different transcriptional regulation of $C A V 1$ may be owing to the different chemotherapeutic drug treatments with MCF-7 cells.

Cav1 can affect the apoptotic process by regulating the expression and activation of downstream proteins. Reduced expression levels of Cav1 in CAFs lead to upregulation of tumor protein 53-induced glycolysis and apoptosis regulator (TIGAR) in the BT474 cells, which functions to limit ROS, thus preventing cells from ROS-induced apoptosis. ${ }^{59}$ Docosahexaenoic acid (DHA) can facilitate caveolae internalization by sensitizing caveolae marker Cav1 to lysosomal marker LAMP-1, thereby decreasing caveolae-associated onco-protein levels via proteasomal and lysosomal pathways and decreasing HSP90 function. ${ }^{70}$

As mentioned above, we demonstrate that the interaction between Cav1 and breast cancer cell apoptosis can be summarized as follows: 1) Cav1 can regulate intrinsic and extrinsic apoptotic pathway proteins, such as Bcl-2, Bax and caspase-3; 2) Cav1-induced autophagy alternation can 
influence cell apoptosis; 3) chemotherapeutic drugs can regulate transcriptional level of $C A V 1$ promoting apoptosis; and 4) Cav1 can affect apoptosis process by regulating the expression and activation of downstream proteins, such as TIGAR, ROS and onco-proteins.

\section{Cavl and breast cancer cell invasion and migration}

It is clear that epithelial to mesenchymal transition (EMT) plays a critical role in cancer progression and metastasis, and Cav1 is implicated in various aspects of EMT, thus driving breast cancer progression. ${ }^{71-73}$ The downregulation of epithelial markers (eg, E-cadherin and $\gamma$-catenin), upregulation of mesenchymal markers (eg, vimentin, fibronectin and N-cadherin) and transcription factors (eg, Snail and Slug) together with the acquisition of increased invasion, migration and stem-like properties are key features of the EMT program. ${ }^{74-76}$ Matrix metalloproteinases (MMPs) are major extracellular enzymes with the capacity of degrading and remodeling extracellular matrix (ECM) proteins and basement membranes, resulting in local invasion, ${ }^{77-79}$ thus promoting cancer initiation, progression, invasion, migration and metastasis. ${ }^{80}$

During hyperglycemia-induced matrix-specific EMT, inhibition of fatty acid synthase/ER $\alpha$ signaling leads to a dramatic upregulation of Cav1 mRNA and protein, thereby enhancing Slug mRNA levels and promoting invasion capacity in MCF-7 and T47D cells. ${ }^{81}$ Fucose-containing fraction of Ling-Zhi (FFLZ) inhibits the Cav-1/Smad7/Smurf2dependent ubiquitin-mediated transforming growth factor- $\beta$ receptor (TGFR) degradation and abolishes TGFR signaling pathways, thereby reducing the expression of EMT markers (eg, Snail and Slug) and suppressing 4T1 and MDA-MB-231 cells migration. ${ }^{82}$ In an vitro study, Cav1 and EMT-related gene expression inhibition was observed in curcumin ${ }^{83}$ and pamidronate ${ }^{84}$-treated MCF-10F cells.

Cav1 knockdown can inhibit BT474 cell invasion and migration capacities via downregulating the protein expression of MMP-2, MMP-9 and MMP-1. ${ }^{50}$ Antarctic krill DHA enhanced the interaction between CD95 (known as Fas) and Cav1, resulting in the downregulation of MMP-2 expression through the inhibition of FAK/SRC/PI3K/AKT signaling pathway in MCF-7 cells. ${ }^{85,86}$ Cav1 and MMP-14 overexpression was observed in malignant and invasive CMT tissues. ${ }^{18}$

Rho GTPases play a key role in the process of microtubule cytoskeleton or actin regulation and thus regulate cell adhesion and migration. ${ }^{87}$ Activation of Cav1 in IBC cells resulted in increasing invasive potential via Akt1 pathway, which phosphorylates RhoC GTPase. ${ }^{88}$ Yang et al found that whether upregulation or downregulation of ROS, the migration capacity of MCF-7 and MDA-MB-231 cells was obviously inhibited via reducing the interaction between Cav1 and DLC1 $1{ }^{89}$ which belongs to the Rho GTPase-activating protein (GAP) family. ${ }^{90}$ Díaz et al reported that Cav1 can recruit $\mathrm{p} 85 \alpha$ (a Rab5 GAP) and thus precluding p85o-mediated Rab5 inactivation, and activated Rab5 can increase Rac1 activity and enhance MDA-MB-231 cells migration and invasion. ${ }^{91}$

Endocytic trafficking of integrins plays a significant role in cell adhesion and migration, which are related to cancer cell dissemination. Focal adhesion associated kinases (FAK)induced phosphorylation of Cav1 on Tyr14 can internalize ligand-bound integrins to early endosomes; pro-metastatic protein NEDD9-dependent dephosphorylation of pTyr14Cav1 is required for the transformation of early endosomes to late endosomes and this leads to individual MDA-MB-231 cell migration. ${ }^{92}$

As mentioned above, we demonstrate that Cav1 can affect breast cancer cell invasion and migration by 1) influencing the expression level of EMT-associated markers and transcription factors; 2) affecting the expression level of MMP; 3) regulating the expression of Rho GTPases and 4) participating Cav1-dependent trafficking of integrins.

\section{Cavl and breast cancer metastasis}

Proliferation, cell cycle arrest, cell transport, adherence, extravasation, motility, adhesion local invasion and migration are necessary preparation for breast cancer metastasis and the prognosis of metastatic breast cancer patients is still poor. ${ }^{93,94}$ Various steps are involved in the cancer metastasis process, including tumor cell detachment and escape, survival in the circulatory system and ultimately growth in distant organs. ${ }^{95,96}$ Once normal epithelial cells detach from the surrounding ECM, a form of programmed apoptosis termed anoikis will be triggered. ${ }^{97}$ To survive in the circulatory and lymphatic system, circulating tumor cells (CTCs) must acquire the ability to resist anoikis, thereby facilitating secondary tumor formation in distant sites. ${ }^{98,99}$ Some metastatic tumor cells are less sensitive or even resistant to anoikis and can survive without attachment to ECM. ${ }^{100}$

Cav1 regulates breast cancer metastasis via participating in anoikis progression. Once MDA-MB-231 cells detach from the ECM and enter into a hemodynamic environment, expression of Cav1 mRNA and protein is enhanced by the fluid-induced low shear stress and Cav1 can endow cancer cells with anoikis resistance via inactivating caspase-8. ${ }^{101}$ Similarly, Cav1 endows anoikis resistance to MDA-MB-231 
cells via activation of PI3K/AKT and MEK/ERK survival signaling pathways and ITGB1-FAK signaling. ${ }^{102}$

Membrane type 4 matrix metalloproteinase (MT4-MMP) co-localizes with Cav1 at the cell surface, ${ }^{103}$ and Cdc42-mediated MT4-MMP internalization and recycling can promote breast cancer metastasis. ${ }^{104}$ Enhanced VEGF-A/VEGFR1 activity upon Cav1 loss in metastasis-associated macrophages drives the downstream expression of MMP9 and colonystimulating factor 1, altogether facilitating angiogenesis and metastatic growth. ${ }^{105}$ Macrophage migration inhibitory factor-induced Cav1 phosphorylation contributes to HMGB1 secretion from the cytoplasm to the ECM, thereby activating TLR4 signaling and promoting breast cancer metastasis. ${ }^{106}$

Alevizos et al found that breast cancer nodal metastasis correlates with extended methylation of Cav1 and CXCR4 in tumors and lymph nodes. ${ }^{107}$ A negative correlation between Cav1 expression and metastatic potential was observed in the breast cancer cell lines. ${ }^{108}$ Genomic and expression profiling reveal Cav1 is upregulated in bone marrow disseminated breast cancer cells relative to CTCs. ${ }^{109}$

As mentioned above, we demonstrate that the interaction between Cav1 and breast cancer metastasis can be summarized as the following: 1) Cav1 can regulate breast cancer metastasis via participating in anoikis progression; 2) Cav1 regulating the expression and transport of metastasisassociated proteins, such as MT4-MMP, MMP9 and TLR4 and 3) the expression levels and methylation of Cav1 are associated with metastatic breast cancer.

\section{Cavl and chemotherapeutics and radiotherapy resistance}

Drug resistance is regarded as one of the most important factors influencing the prognosis of cancer patients. ${ }^{110}$ Thirty percent early breast cancer patients develop metastatic disease with the majority of these being resistant to current chemotherapies. ${ }^{111}$ Cav1 was a potential target for preventing cancer radiation and drug resistance and improving clinical outcomes. ${ }^{112,113}$

With the capacity of mediating chemically cytostatic drugs efflux, breast cancer resistance proteins (BCRP) play an important role in clinical breast cancer drug resistance. ATP-binding cassette subfamily G member 2 (ABCG2) is one of the BCRPs. An elevated Cav1 mRNA and protein expression level was observed in TNBC stem cells, altogether enhancing expression level of ABCG2 via downregulating the Cav1-related $\beta$-catenin proteasomal degradation pathway and upregulating intracellular $\beta$-catenin accumulation. ${ }^{114}$ Similarly, Herzog et al also found that knockdown of Cav1 decreased activity of ABCG2 and sensitized drug resistant breast cancer cells to chemotherapeutics. ${ }^{115}$

Trastuzumab emtansine (T-DM1) is an antibody drug conjugate (ADC) that has been approved by the US Food and Drug Administration to treat HER-2-positive metastatic breast cancer. ${ }^{116,117}$ The trastuzumab in T-DM1 can bind to HER-2 receptors, followed by internalization of T-DM1 into cells and release of emtansine, resulting in cell toxicity. ${ }^{118}$ Recent studies demonstrated that Cav1 can co-localize with trastuzumab to mediate T-DM1 internalization and enhance drug toxicity. ${ }^{119}$ The elevated Cav1 expression could mediate endocytosis and promote the internalization of T-DM1 into HER2-positive cancer cells. ${ }^{120}$ Chung et al reported that Cav1 in BT-474 cells enhanced drug sensitivity by promoting T-DM1 internalization. ${ }^{121}$ It is worth mentioning that mRNA profiling reveals that low Cav1 expression seems to sensitize BT474 cells to T-DM1. ${ }^{122}$ And, in addition to internalization, Cav1 can mediate N87-TM cells' resistance to T-DM1 via altering endocytic ADC to the lysosome and degrading T-DM1. ${ }^{123}$

Cav1 overexpression in MCF-7 and MDA-MB-231 cell lines abolished the chemosensitizing effects by inhibiting eNOS/NO/ONOO- pathway and oxidant damage. ${ }^{124}$ In $\mathrm{ER}(+)$ breast cancer cells, the MAPK pathway induced by Src phosphorylation can further phosphorylate Cav1, which activates the ER pathway and confers acquired resistance to lapatinib. ${ }^{125}$ Radiation-induced Cav1 elevation promotes EGFR nuclear translocation and activates DNA-dependent protein kinase, following DNA repair and formation of radiation resistance. ${ }^{126}$

As mentioned above, we demonstrate that Cav1 can affect breast cancer cell chemotherapeutics and radiotherapy resistance by 1) affecting the expression and activity of BCRP (eg, ABCG2); 2) influencing Cav-1-mediated T-DM1 internalization; 3) regulating eNOS/NO/ONOO- pathway and ER pathway and 4) promoting repair of radiation-induced DNA damage.

\section{Cavl and cancer stem cell}

Tumor initiation is closely related to resistance to chemotherapeutics and radiotherapy resistance, and various approaches have been hypothesized to solve this issue. ${ }^{127}$ Over the past decades, few researchers have addressed the issue of reversing drug resistance. ${ }^{128,129}$ Cancer stem cell (CSC) is increasingly set to become a vital factor in resistance to chemotherapeutics or radiotherapy, and it has been considered as a potential pathway for tumor recurrence in a variety of cancers, which significantly influences the clinical outcomes of patients. ${ }^{110,130-132}$ This means, if a therapeutic agent fails to 
kill all the CSCs, the tumor may regrow. ${ }^{133}$ One of the main issues in our knowledge of CSC is a lack of discovering the regulation behind recurrence of drug resistance. ${ }^{134-136}$

For breast cancer, CD44+/CD24-/lin-cell population was demonstrated as meeting the characteristics of CSCs. What is more, this cell population showed enhanced invasive properties but did not translate into real metastasis. ${ }^{137}$ Wang et al discovered the role of Cav1 in mediating the chemoresistance of breast CSCs via silencing Cav1 in breast cancer stem cells (BCSCs), limited self-renewal ability but inducing the differentiation process of BCSCs by downregulating the $\beta$-catenin/ ABCG2 pathway. Their clinical investigation supported the results in MCF-7 and MDA-MB-231 human breast cancer cell lines, revealing that Cav1 was highly elevated in TNBC. Moreover, Cav1 silencing significantly impaired the tumorigenicity and chemoresistance of breast CSCs in in vivo models. ${ }^{114}$

Yuan's group found that epirubicin increased the activity of the human Wnt6 promoter through Cav1-dependent binding of $\beta$-catenin to the proximal Wnt6 promoter in gastric cancer, which is considered an important regulator of CSCs. ${ }^{138}$ Another regulator seems related to TME. Yongsanguanchai et al suggested that rapid reversible changes of CSC-like cells within tumors may result from biological mediators found in the TME, such as nitric oxide, which was elevated in H292 and H460 cells, and could promote CSC-like phenotypes of human non-small-cell lung carcinoma via Cav1 upregulation. ${ }^{139}$

In sum, current studies focusing on the relationship between therapeutic resistance and Cav1 are still restricted to a few cancer types. Besides, a more comprehensive approach is required to identify the crucial role of Cav1 in cancer relapse to identify the physiological function and molecular networks that maintain stem cell survival in response to different treatments.

\section{Cavl and breast cancer prognosis}

Cav1 is emerging as a potential therapeutic biomarker for breast cancer treatments. ${ }^{40}$ Epithelium Cav1 and stroma Cav1 may be useful as prognostic indicators for patient treatments and assist the selection of personalized therapy. ${ }^{141}$ Both the epithelial and stromal Cav1 have been detected in breast cancer patients and can be used to forecast the prognosis. Breast cancer patients with negative Cav1 expression in CAFs often show a poor outcome and low survival rate. ${ }^{142,143}$ Absence of Cav1 expression in CAFs allows patients with lymph node metastasis and poor prognosis. ${ }^{7}$ Lack of stromal Cav1 expression is associated with a poor prognosis and worse overall survival. ${ }^{144-146}$ High expression level of Cav1 in invasive breast cancer cells indicates that epithelial Cav1 expression is proportional to tumor aggressiveness and poor prognosis. ${ }^{140,147}$ Besides, Qian et al reported that tumor $(++) /$ stromal (-) Cav1 expression was closely associated with poor prognostic outcomes in primary human breast cancer patients. ${ }^{148}$

In addition to the breast cancer cells with low stromal Cav1 expression (38.56\%), Liang et al also found overexpression of cytoplasmic EGFR (53.92\%) and Cav1 (44.12\%), and suggested the combined stromal Cav-1/EGFR expression as an advanced prognostic marker. ${ }^{47}$ It is also reported that lack of Cav1 and overexpression of monocarboxylate transporter 4 (MCT-4) in stroma show a prognostic significance to breast cancer patients. ${ }^{149}$

As mentioned above, we demonstrate that stromal Cav1 expression may be a potential prognostic indicator for breast cancer patients and loss of stromal Cav1 expression often shows a poor clinical outcome. What is more, high expression levels of epithelial Cav1, cytoplasmic EGFR and stromal MCT-4 may be secondary prognostic indicators (Figure 2).

\section{Conclusion and future perspective}

Nowadays, breast cancer is one of the most common cancer diseases and causes of death among female population worldwide. Human breast cancer shows different pathological types, including non-invasive breast cancer, invasive breast carcinoma of special type, invasive breast carcinoma of no special type, IBC and so on. Different pathological types of breast cancer show different epidemiological characteristics and prognosis: invasive lobular carcinoma is the second most common subtype of mammary cancer to invasive ductal carcinoma, ${ }^{150}$ non-invasive breast cancer is a type of breast cancer with a better prognosis, while IBC patients often show a poor prognosis. According to whether the cancer cell plasma membrane expresses ER, PR and HER2, mammary cancer can be divided into luminal A, luminal B, normal breast-like, HER-2 over-expressing and basal-like breast cancer. TNBC is a subtype of basal-like breast cancer with poor prognosis. Cav1 is the main component of caveolae, and it participates in various biological events. It has been reported that genetic changes of Cav1 might modify the risk for breast cancer, ${ }^{151}$ and Cav1 acts both as a tumor suppressor as well as an oncogene, and plays a key role in breast cancer tumorigenesis. ${ }^{152}$ In addition to breast cancer carcinogenic process, Cav1 is also associated with lung cancer, ${ }^{153,154}$ colorectal cancer, ${ }^{155}$ gastric cancer, ${ }^{156,157}$ cervical cancer, ${ }^{158}$ hepatocellular carcinoma, ${ }^{159}$ pancreatic cancer, ${ }^{160}$ bladder cancer, ${ }^{161}$ pulmonary hypertension, ${ }^{162-164}$ virus infection, ${ }^{165,166}$ cardiovascular disease, ${ }^{167,168}$ diabetes mellitus, ${ }^{169}$ nanomedicines endocytosis ${ }^{170}$ 


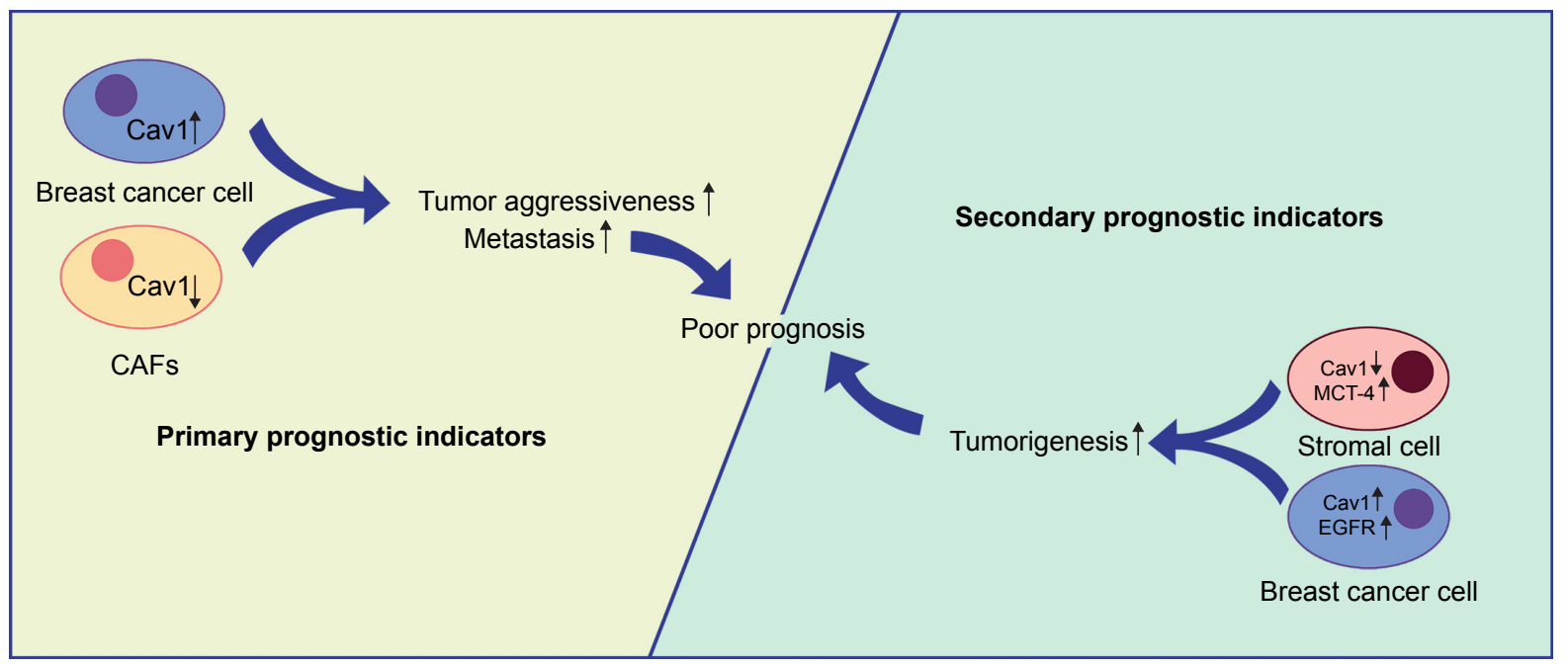

Figure 2 Cavl and breast cancer prognosis.

Notes: CAFs and epithelium Cavl expression may be primary prognostic indicators for breast cancer patients. Loss of CAFs Cavl expression and high expression levels of epithelium Cavl often show a poor clinical outcome. Moreover, cytoplasmic EGFR and stromal MCT-4 may be secondary prognostic indicators.

Abbreviations: CAFs, cancer-associated fibroblasts; Cavl, caveolin-I; MCT-4, monocarboxylate transporter 4.

and lipodystrophy. ${ }^{171}$ Besides, it has been reported that caveolin-2 (Cav2) can also mediate the initiation and development of breast cancer. ${ }^{26}$

We discuss the role of Cav1 in ER-positive or -negative breast cancer, and notice several contrary results. With regard to cancer cell apoptosis, Chintala et al noted that downregulation of tumor promoter Cav1 by M $\beta C D$ contributed to MDA-MB-231 (ER-) apoptosis. ${ }^{65}$ Their results were contradicted by the experiments of Kang et al, who showed that elevated expression level of Cav1 exposed TNBC cells (MDA-MB-231 cells) to the apoptotic process that suggested Cav1's role as a tumor suppressor. ${ }^{51}$ With regard to chemotherapeutics and radiotherapy resistance, Cav1, considered as a tumor suppressor, was phosphorylated by MAPK pathway and conferred acquired resistance to lapatinib in $\mathrm{ER}(+)$ breast cancer cells. ${ }^{125}$ However, interestingly, this is contrary to the results of a study conducted by Zou et al in TNBC cells that demonstrated Cav1 as a tumor promoter via promoting DNA repair and formation of radiation resistance. ${ }^{126}$ From the aspect of effect of Cav1 in these cases, conclusions seem totally contrary. Among the plausible explanations for these findings are different cell lines and signaling pathways, indicating whether ER expressed in different types of BC may result in diverse interaction with Cav1 and signaling pathways.

In the current review, we found that Cav1 acts both as a tumor suppressor as well as a promoter, and plays a key role in breast cancer tumorigenesis (Figure 3). We also summarized the role of Cav1 in the development of breast cancer, in the hope of providing a basis for molecular targeted therapy of breast cancer (Tables 1 and 2). We have demonstrated the interaction between Cav1 and human breast cancer.

1. Cav1 can affect breast cancer cell proliferation rate by 1) influencing the expression and activation of ion channels and receptors on the cell membrane, such as $\mathrm{BKCa}$ channel, EGFR and HER2; 2) regulating cell cycle arrest and affecting mitosis process; and 3 ) mediating the interaction between the TME (hypoxia conditions and CAFs) and breast cancer cells.

2. Cav1 can affect breast cancer cell apoptosis by 1) regulating intrinsic and extrinsic apoptotic pathway proteins, such as Bcl-2, Bax and caspase-3; 2) Cav1-induced autophagy alternation can influence cell apoptosis; 3) chemotherapeutic drugs can regulate transcriptional level of $C A V 1$ and promote apoptosis; and 4) regulating the expression and activation of apoptosis-related molecules, such as TIGAR, ROS and onco-proteins.

3. Cav1 can affect breast cancer cell invasion and migration by 1) influencing the expression level of EMT-associated markers and transcription factors; 2) affecting the expression level of MMPs; 3 ) regulating the expression of Rho GTPases and 4) participating Cav1-dependent trafficking of integrins.

4. Cav1 can affect breast cancer metastasis by 1) participating in anoikis progression; 2) regulating the expression and transport of metastasis-associated proteins, such as MT4-MMP, MMP9 and TLR4 and 3) the expression levels and methylation of Cav1 are associated with metastatic breast cancer. 


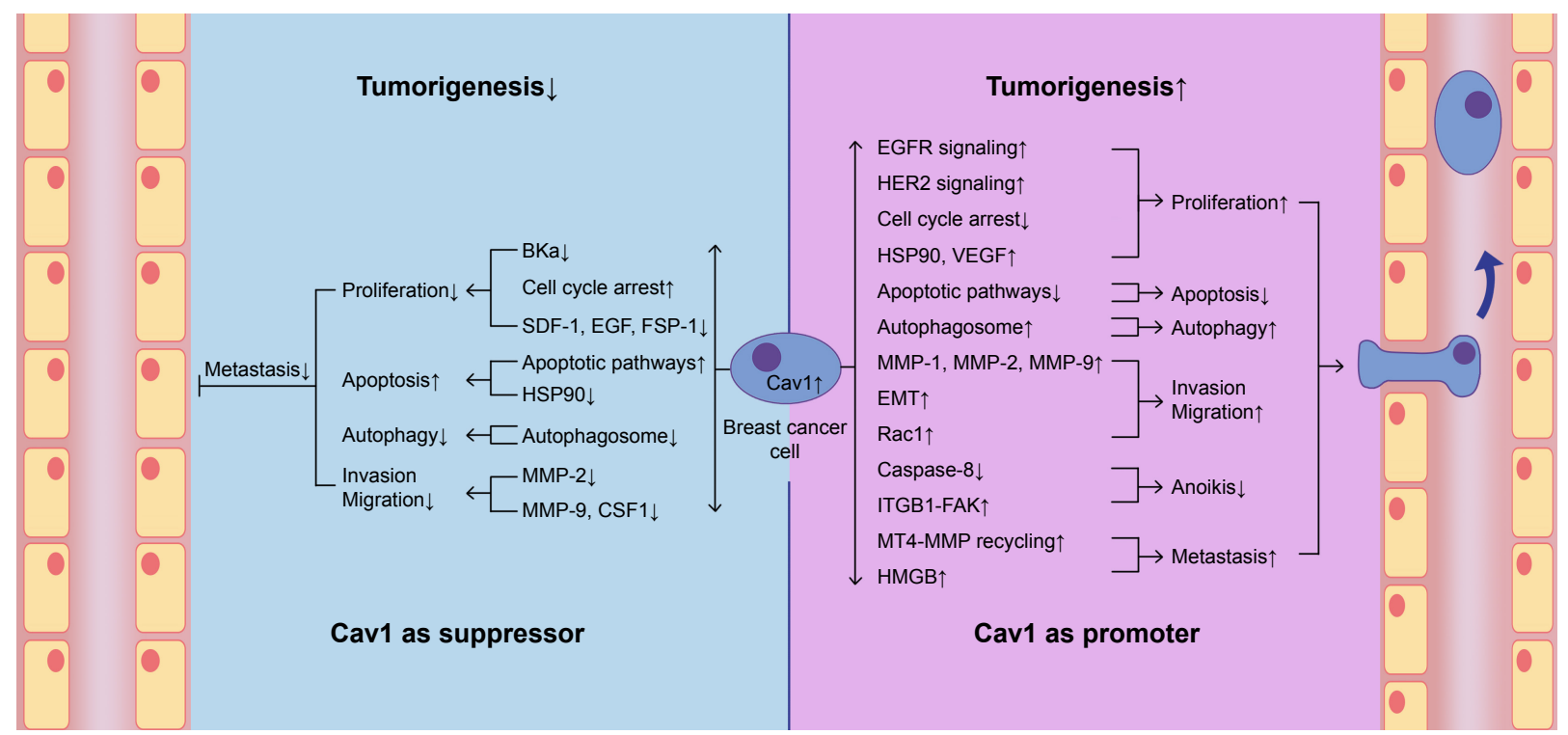

Figure $3 \mathrm{Cavl}$ acts both as a suppressor and a promoter in breast cancer cell tumorigenesis.

Notes: Cavl can act as a suppressor in breast cancer cell carcinogenic process via suppressing breast cancer cell proliferation, autophagy, invasion and migration and promoting apoptosis. Cavl can also act as a promoter in breast cancer cell carcinogenic process via promoting breast cancer cell proliferation, autophagy, invasion, migration and metastasis, and suppressing apoptosis and anoikis.

Abbreviations: BKCa, large conductance $\mathrm{Ca}^{2+}$-activated potassium; CavI, caveolin-I; CSFI, colony-stimulating factor I; EMT, epithelial to mesenchymal transition; FSP-I, fibroblast-specific protein-I; HER2, human epidermal growth factor receptor-2; HSP90, heat shock protein 90; MMP, matrix metalloproteinase; MT4-MMP, membrane type 4 matrix metalloproteinase; VEGF, vascular endothelial growth factor; SDF-I, stromal cell-derived factor-I.

5. Cav1 can affect breast cancer cell chemotherapeutics and radiotherapy resistance by 1) affecting the expression and activity of BCRP (eg, ABCG2); 2) influencing Cav-1-mediated T-DM1 internalization; 3) regulating eNOS/NO/ONOO- pathway and ER pathway and 4) promoting repair of radiation-induced DNA damage.

6. Stromal Cav1 expression may be a potential prognostic indicator for breast cancer patients and loss of stromal Cav1 expression often show a poor clinical outcome. What is more, high expression levels of epithelial Cav1, cytoplasmic EGFR and stromal MCT-4 may be secondary prognostic indicators.

The molecular pathways that Cav1 impacts and breast cancer are interrelated. EGFR and HER2 are receptors on the breast cancer cell membrane, and Cav1 promotes breast cancer cell proliferation via EGFR or HER2-induced mitogenic signaling pathway. Besides, the regulation of cell cycle-associated proteins (eg, cyclin B1, cyclin D1, cyclin D2 and $\beta$-catenin) is a significant way that Cav1 affects the cell proliferation rate. The activation of ERK pathway not only promotes the proliferation but also endows anoikis resistance to cancer cells, ultimately promoting the progression of breast cancer. High oxidative stress promotes cell proliferation by regulating Cav1, and Cav1 can also promote cell apoptosis via activating ROS pathway and chemotherapeutics resistance via regulating oxidative damage. VEGF is another targeted molecule in Cav1-mediated breast cancer tumorigenesis. Activation of Cav1 upregulates VEGF and promotes cell proliferation, contrarily, Cav1 loss enhances VEGF-A/VEGFR1 activity and facilitates angiogenesis and metastatic growth. The regulation of intrinsic and extrinsic apoptotic pathwayrelated molecules (eg, survivin, Bcl-2, Bax caspase- 8 and caspase-3) is an important process in Cav1-induced apoptosis, and inactivation of caspase- 8 can inhibit apoptosis and endow anoikis resistance to cancer cell. MMPs (eg, MMP-1, MMP-2, MMP-9, MMP-14 and MT4-MMP) are key proteins in the EMT process that promotes breast cancer invasion, migration and metastasis. Cav1-induced MMP-2 upregulation promotes BT474 cells' invasion and migration, while Cav1 can also downregulate the expression of MMP-2 in MCF-7 via inhibiting PI3K/AKT signaling pathway and ultimately suppressing invasion and migration. Cav1-mediated PI3K/AKT signaling pathway activation can promote anoikis resistance. To sum up, Cav1-mediated breast cancer progression-related molecular pathways are correlational, it not only shows the same or opposite effect in the same stage but also in different stages.

Caveolae are cholesterol-enriched rigid membrane microdomains that are composed of caveolins, including Cav1, Cav2 and Cav3. Therefore, the treatment of breast cancer may be achieved by targeting Cav1. First, the use of 
Table I The role of CavI in breast cancer cells tumorigenesis

\begin{tabular}{|c|c|c|c|c|}
\hline Progress stages & Cell lines & Signaling cascades & $\begin{array}{l}\text { Promoterl } \\
\text { suppressor }\end{array}$ & References \\
\hline $\begin{array}{l}\text { Proliferation, } \\
\text { invasion }\end{array}$ & MCF-7 & $\mathrm{Cavl} \uparrow \rightarrow \mathrm{BKCa} \downarrow$ & Suppressor & 46 \\
\hline Proliferation & SKBR3 BT-474 & $\gamma$-tocotrienol $\rightarrow$ caveolae disruption $\rightarrow$ HER2 signaling $\downarrow$ & Promoter & 49 \\
\hline $\begin{array}{l}\text { Proliferation, } \\
\text { invasion, migration }\end{array}$ & BT-474 & $\begin{array}{l}\text { CavI } \uparrow \rightarrow \text { cell cycle arrest } \downarrow \\
\text { CavI } \downarrow \rightarrow \text { MMP-2, MMP-9, MMP-I } \downarrow\end{array}$ & Promoter & 50 \\
\hline Proliferation & MDA-MB-23I MCF-7 & CavI $\uparrow \rightarrow$ cell cycle arrest $\uparrow$ & Suppressor & 51 \\
\hline Proliferation & MDA-MB-23I & $\mathrm{BPA} \rightarrow \mathrm{Cavl-GPER} \uparrow \rightarrow \mathrm{HSP} 90, \mathrm{HIF}-\mathrm{I} \alpha, \mathrm{VEGF} \uparrow$ & Promoter & 52,58 \\
\hline Proliferation & BT-474 & CAFs CavI $\downarrow \rightarrow$ SDF-I, EGF, FSP-I $\uparrow$ & Suppressor & 59 \\
\hline Apoptosis & $\begin{array}{l}\text { MDA-MB-23I } \\
\text { MDA-MB-468 }\end{array}$ & $\mathrm{M} \beta C D \rightarrow$ CavI $\downarrow \rightarrow$ apoptotic pathways $\uparrow$ & Promoter & 65 \\
\hline Apoptosis & MDA-MB-23I MCF-7 & CavI $\uparrow \rightarrow$ apoptotic pathways $\uparrow$ & Suppressor & 51 \\
\hline Autophagy & BT-474 & E2 $\rightarrow$ CavI $\uparrow \rightarrow$ autophagosome $\uparrow$ & Promoter & 66 \\
\hline Autophagy & MCF-7 & $\begin{array}{l}\text { Cavl } \downarrow \rightarrow \text { V-ATPase assembly } \uparrow \rightarrow \text { autophagosome- } \\
\text { lysosome fusion } \uparrow\end{array}$ & Suppressor & 67 \\
\hline Apoptosis & MCF-7 & Fluvastatin $\rightarrow$ CAVI mRNA expression $\downarrow$ & Promoter & 68 \\
\hline Apoptosis & MCF-7 & Metformin $\rightarrow$ CAVI mRNA expression $\uparrow$ & Suppressor & 69 \\
\hline Apoptosis & MDA-MB-23I SK-BR-3 & $\mathrm{DHA} \rightarrow \mathrm{CavI} \uparrow \rightarrow$ onco-proteins, HSP90 $\downarrow$ & Suppressor & 70 \\
\hline Invasion, migration & $\begin{array}{l}\text { MCF-7 } \\
\text { T47D }\end{array}$ & Cavl $\uparrow \rightarrow$ Slug $\uparrow \rightarrow \mathrm{EMT} \uparrow$ & Promoter & 81 \\
\hline Invasion, migration & $\begin{array}{l}\text { MDA-MB-23I } \\
4 \mathrm{TI}\end{array}$ & $\begin{array}{l}\text { FFLZ } \rightarrow \text { Cav-I/Smad7/Smurf2 } \downarrow \rightarrow \text { TGFR signaling } \downarrow \rightarrow \\
\text { EMT } \downarrow\end{array}$ & Promoter & 82 \\
\hline Invasion, migration & MCF-IOF & Curcumin, pamidronate $\rightarrow$ CavI $\downarrow \rightarrow$ EMT $\downarrow$ & Promoter & 83,84 \\
\hline Invasion & MCF-7 & Antarctic krill DHA $\rightarrow$ CavI-Fas $\uparrow \rightarrow$ MMP- $2 \downarrow$ & Suppressor & 86 \\
\hline Migration & MDA-MB-23I MCF-7 & ROS $\rightarrow$ Cavl-GAP $\downarrow$ & Promoter & 90 \\
\hline Invasion, migration & MDA-MB-23I & $\operatorname{Cavl} \uparrow \rightarrow \operatorname{Rab} 5 \uparrow \rightarrow \operatorname{Racl} \uparrow$ & Promoter & 91 \\
\hline Anoikis & MDA-MB-23I & LSS $\rightarrow$ CavI $\uparrow \rightarrow$ caspase-8 $\downarrow \rightarrow$ anoikis $\downarrow$ & Promoter & 101 \\
\hline Anoikis & MDA-MB-23I & CavI $\uparrow \rightarrow$ ITGBI-FAK $\uparrow \rightarrow$ anoikis $\downarrow$ & Promoter & 102 \\
\hline Metastasis & MDA-MB-23I & CavI $\uparrow \rightarrow$ MT4-MMP recycling $\uparrow$ & Promoter & 104 \\
\hline Metastasis & E077I & CavI $\downarrow \rightarrow$ VEGF-A/VEGFRI $\uparrow \rightarrow$ MMP9, CSFI $\uparrow$ & Suppressor & 105 \\
\hline Metastasis & $\begin{array}{l}\text { MDA-MB-23I } \\
\text { MCF-7 } \\
\text { T47D }\end{array}$ & $\begin{array}{l}\text { MIF } \rightarrow \text { Cavl phosphorylation } \uparrow \rightarrow \mathrm{HMGBI} \uparrow \rightarrow \text { TLR4/ } \\
\text { NF-kappa B } \uparrow\end{array}$ & Promoter & 106 \\
\hline Drug resistance & MCF-7 MDA-MB-23I & Cavl $\uparrow \rightarrow \mathrm{ABCG} 2 \uparrow \rightarrow$ drug resistance $\uparrow$ & Promoter & 114 \\
\hline Drug resistance & BT-474 & CavI $\uparrow \rightarrow$ T-DMI internalization $\uparrow$ & Suppressor & 121 \\
\hline Drug resistance & MCF-7 & Cavl $\uparrow \rightarrow$ eNOS/NO/ONOO- $\downarrow$ & Promoter & 124 \\
\hline Radiation resistance & BT474 SKBR3 MDA-MB-23I & CavI $\uparrow \rightarrow$ EGFR nuclear translocation $\uparrow \rightarrow$ DNA repair $\uparrow$ & Promoter & 126 \\
\hline
\end{tabular}

Abbreviations: ABCG2, ATP-binding cassette subfamily G member 2; BKCa, large conductance $\mathrm{Ca}^{2+}$-activated potassium; BPA, Bisphenol A; CAFs, cancer-associated fibroblasts; CavI, caveolin-I; CSFI, colony-stimulating factor I; DHA, docosahexaenoic acid; EMT, epithelial to mesenchymal transition; FAK, focal adhesion associated kinases; FFLZ, fucose-containing fraction of Ling-Zhi; FSP-I, fibroblast-specific protein-I; GAP, GTPase-activating protein; GPER, G-protein estrogen receptor; HER2, human epidermal growth factor receptor-2; HIF-I $\alpha$, hypoxia inducible factor-I alpha; HSP90, heat shock protein 90; LSS, fluid-induced low shear stress; MIF, migration inhibitory factor; MMP, matrix metalloproteinase; MT4-MMP, membrane type 4 matrix metalloproteinase; M $\beta C D$, methyl beta cyclodextrin; SDF-I, stromal cell-derived factor-I; T-DMI, trastuzumab emtansine; TGFR, transforming growth factor- $\beta$ receptor; VEGF, vascular endothelial growth factor.

targeted drugs (eg, $\gamma$-tocotrienol and $\mathrm{M} \beta \mathrm{CD})$ to accumulate within the caveolae microdomain, thereby disrupting the structure of caveolae and blocking the Cav1-mediated signaling pathway, may be a means of breast cancer-targeted therapy. ${ }^{49,65,67}$ Second, targeted drug-induced regulation of Cav1 expression level may be another targeted treatment. ${ }^{51}$ Besides, targeted drugs (eg, FFLZ and antarctic krill DHA) regulate the activation of Cav1 and Cav1-mediated 
Table 2 The role of Cavl in breast cancer tissues tumorigenesis

\begin{tabular}{|l|l|l|l|l|}
\hline Progress stages & Tissues & Signaling cascades & Promoter/suppressor & References \\
\hline Proliferation & Breast cancer tissues & CavI $\uparrow \rightarrow$ EGFR signaling $\uparrow$ & Promoter & 47 \\
\hline Proliferation & Breast cancer tissues & Stromal CavI $\downarrow \rightarrow$ epithelium CavI $\downarrow$ & Suppressor & 54 \\
\hline Invasion, migration & CMT tissues & CavI, MMP-I4 $\uparrow$ & Promoter & 18 \\
\hline
\end{tabular}

Abbreviations: Cavl, caveolin-I; CMT, canine mammary tumor; MMP, matrix metalloproteinase.

signaling cascades, ultimately inhibiting the progression of breast cancer. ${ }^{82,86}$ More importantly, targeted drugs (eg, DHA and T-DM1) can facilitate caveolae-mediated chemotherapy drug internalization by sensitizing caveolae marker Cav1, thus preventing drug resistance and improving therapeutic effect. ${ }^{70,119}$

Although we have summarized the relationship between Cav1 and a certain tumor progression process in this review, the effect of Cav1 on the development of breast cancer is continuous and multi-process (Tables 1 and 2). ${ }^{172}$ Apoptosis and cell proliferation are mutually restricted; autophagy can promote cell renewal and inhibit apoptosis and invasion and migration are necessary preparations for distant metastasis. It can be seen that the occurrence and tumorigenesis of breast cancer is a continuous process, and the influence of Cav1 is multi-stage and continuous. Above all, we believe the summary of the interaction between Cav1 and breast cancer can be a basis for further research and promote $C A V 1$ gene as a potential target to diagnose and treat aggressive breast cancer.

\section{Disclosure}

LXX received a grant from the National Natural Science Foundation of China (No 31860317). The authors report no other conflicts of interest in this work.

\section{References}

1. Harbeck N, Gnant M. Breast cancer. Lancet. 2017;389(10074):1134-1150.

2. Anwar SL, Wahyono A, Aryandono T, Haryono SJ. Caveolin-1 in breast cancer: single molecule regulation of multiple key signaling pathways. Asian Pac J Cancer Prev. 2015;16(16):6803-6812.

3. Ward EM, Desantis CE, Lin CC, et al. Cancer statistics: breast cancer in situ. CA Cancer J Clin. 2015;65(6):481-495.

4. Desantis CE, Ma J, Goding Sauer A, Newman LA, Jemal A. Breast Cancer statistics, 2017, racial disparity in mortality by state. CA Cancer J Clin. 2017;67(6):439-448.

5. Wachter DL, Wachter PW, Fasching PA, et al. Characterization of molecular subtypes of Paget disease of the breast using immunohistochemistry and in situ hybridization. Arch Pathol Lab Med. 2019;143(2): 206-211.

6. Vranic S, Marchiò C, Castellano I, et al. Immunohistochemical and molecular profiling of histologically defined apocrine carcinomas of the breast. Hum Pathol. 2015;46(9):1350-1359.

7. Ren M, Liu F, Zhu Y, et al. Absence of caveolin-1 expression in carcinomaassociated fibroblasts of invasive micropapillary carcinoma of the breast predicts poor patient outcome. Virchows Arch. 2014;465(3):291-298.
8. Wang C, Ye Q, Cao Y, et al. Downregulation of regulator of G protein signaling 2 expression in breast invasive carcinoma of $\mathrm{NO}$ special type: clinicopathological associations and prognostic relevance. Oncol Lett. 2018;15(1):213-220.

9. Selvi V, Nori J, Meattini I, et al. Role of magnetic resonance imaging in the preoperative staging and work-up of patients affected by invasive lobular carcinoma or invasive ductolobular carcinoma. Biomed Res Int. 2018;2018:1-7.

10. Obeidat FN, Ahram M, Al-Khader A, et al. Expression of androgen receptor in invasive ductal breast carcinomas: a clinicopathological study from Jordan. Ann Saudi Med. 2018;38(5):326-335.

11. Sørlie T, Perou CM, Tibshirani R, et al. Gene expression patterns of breast carcinomas distinguish tumor subclasses with clinical implications. Proc Natl Acad Sci U S A. 2001;98(19):10869-10874.

12. Jhan JR, Andrechek ER. Triple-negative breast cancer and the potential for targeted therapy. Pharmacogenomics. 2017;18(17):1595-1609.

13. Aysola K, Desai A, Welch C, et al. Triple negative breast cancer - an overview. Hereditary Genet. 2013;2013(Suppl 2).

14. Cheng CL, Thike AA, Tan SY, Chua PJ, Bay BH, Tan PH. Expression of FGFR1 is an independent prognostic factor in triple-negative breast cancer. Breast Cancer Res Treat. 2015;151(1):99-111.

15. Yue Y, Astvatsaturyan K, Cui X, Zhang X, Fraass B, Bose S. Stratification of prognosis of triple-negative breast cancer patients using combinatorial biomarkers. PLoS One. 2016;11(3):e0149661.

16. Omidvari S, Hamedi SH, Mohammadianpanah M, et al. Very late relapse in breast cancer survivors: a report of 6 cases. Iran J Cancer Prev. 2013;6(2):113-117.

17. Collignon J, Lousberg L, Schroeder H, Jerusalem G. Triple-negative breast cancer: treatment challenges and solutions. Breast Cancer. 2016;8: 93-107.

18. Ebisawa M, Iwano H, Nishikawa M, et al. Significance of caveolin-1 and matrix metalloproteinase 14 gene expression in canine mammary tumours. Vet J. 2015;206(2):191-196.

19. Shinoda H, Legare ME, Mason GL, et al. Significance of ER $\alpha$, HER2, and $\mathrm{CaV} 1$ expression and molecular subtype classification to canine mammary gland tumor. $J$ Vet Diagn Invest. 2014;26(3):390-403.

20. Ettlin J, Clementi E, Amini P, Malbon A, Markkanen E. Analysis of gene expression signatures in cancer-associated stroma from canine mammary tumours reveals molecular homology to human breast carcinomas. Int J Mol Sci. 2017;18(5):E1101.

21. Drews-Elger K, Iorns E, Dias A, et al. Infiltrating S100A8+ myeloid cells promote metastatic spread of human breast cancer and predict poor clinical outcome. Breast Cancer Res Treat. 2014;148(1): $41-59$.

22. Cheng JPX, Nichols BJ. Caveolae: one function or many? Trends Cell Biol. 2016;26(3):177-189.

23. Martinez-Outschoorn UE, Sotgia F, Lisanti MP. Caveolae and signalling in cancer. Nat Rev Cancer. 2015;15(4):225-237.

24. Echarri A, del Pozo MA. Caveolae. Curr Biol. 2012;22(4):R114-R116.

25. Chamberlain LH. Detergents as tools for the purification and classification of lipid rafts. FEBS Lett. 2004;559(1-3):1-5.

26. Totta P, Gionfra F, Busonero C, Acconcia F. Modulation of $17 \beta$-estradiol signaling on cellular proliferation by caveolin-2. J Cell Physiol. 2016; 231(6):1219-1225.

27. Kovtun O, Tillu VA, Ariotti N, Parton RG, Collins BM. Cavin family proteins and the assembly of caveolae. JCell Sci. 2015;128(7):1269-1278. 
28. Wang S, Wang N, Zheng Y, Zhang J, Zhang F, Wang Z. Caveolin-1: an oxidative stress-related target for cancer prevention. Oxid Med Cell Longev. 2017;2017:1-20.

29. Parat MO, Riggins GJ. Caveolin-1, caveolae, and glioblastoma. Neurooncology. 2012;14(6):679-688.

30. Thompson MA, Prakash YS, Pabelick CM. The role of caveolae in the pathophysiology of lung diseases. Expert Rev Respir Med. 2014;8(1): 111-122.

31. Duhon D, Bigelow RLH, Coleman DT, et al. The polyphenol epigallocatechin-3-gallate affects lipid rafts to block activation of the c-met receptor in prostate cancer cells. Mol Carcinog. 2010;49(8):739-749.

32. Pike LJ. Growth factor receptors, lipid rafts and caveolae: an evolving story. Biochim Biophys Acta. 2005;1746(3):260-273.

33. Gleissman H, Segerström L, Hamberg M, et al. Omega-3 fatty acid supplementation delays the progression of neuroblastoma in vivo. Int J Cancer. 2011;128(7):1703-1711.

34. Gupta R, Toufaily C, Annabi B. Caveolin and cavin family members: dual roles in cancer. Biochimie. 2014;107(Pt B):188-202.

35. Quest AF, Lobos-González L, Nuñez S, et al. The caveolin-1 connection to cell death and survival. Curr Mol Med. 2013;13(2):266-281.

36. Peter ME, Hadji A, Murmann AE, et al. The role of CD95 and CD95 ligand in cancer. Cell Death Differ. 2015;22(4):549-559.

37. Chen $\mathrm{D}$, Che $\mathrm{G}$. Value of caveolin-1 in cancer progression and prognosis: emphasis on cancer-associated fibroblasts, human cancer cells and mechanism of caveolin-1 expression (review). Oncol Lett. 2014;8(4): 1409-1421.

38. Al-Ansari MM, Aboussekhra A. Caffeine mediates sustained inactivation of breast cancer-associated myofibroblasts via up-regulation of tumor suppressor genes. PLoS One. 2014;9(3):e90907.

39. Patani N, Martin LA, Reis-Filho JS, Dowsett M. The role of caveolin-1 in human breast cancer. Breast Cancer Res Treat. 2012;131(1):1-15.

40. Mercier I, Lisanti MP. Caveolin-1 and breast cancer: a new clinical perspective. Adv Exp Med Biol. 2012;729:83-94.

41. Fu P, Chen F, Pan Q, et al. The different functions and clinical significances of caveolin-1 in human adenocarcinoma and squamous cell carcinoma. Onco Targets Ther. 2017;10:819-835.

42. Mollinedo F, de La Iglesia-Vicente J, Gajate C, et al. In vitro and in vivo selective antitumor activity of edelfosine against mantle cell lymphoma and chronic lymphocytic leukemia involving lipid rafts. Clin Cancer Res. 2010;16(7):2046-2054.

43. Gajate C, Mollinedo F. Edelfosine and perifosine induce selective apoptosis in multiple myeloma by recruitment of death receptors and downstream signaling molecules into lipid rafts. Blood. 2007;109(2): 711-719.

44. Na HK, Surh YJ. The antitumor ether lipid edelfosine (ET-18-O-CH3) induces apoptosis in H-ras transformed human breast epithelial cells: by blocking ERK1/2 and p38 mitogen-activated protein kinases as potential targets. Asia Pac J Clin Nutr. 2008;17(Suppl 1):204-207.

45. Chantôme A, Potier-Cartereau M, Clarysse L, et al. Pivotal role of the lipid raft SK3-Orail complex in human cancer cell migration and bone metastases. Cancer Res. 2013;73(15):4852-4861.

46. Du C, Chen L, Zhang H, et al. Caveolin-1 limits the contribution of BKCa channel to MCF-7 breast cancer cell proliferation and invasion. Int J Mol Sci. 2014;15(11):20706-20722.

47. Liang YN, Liu Y, Wang L, et al. Combined caveolin-1 and epidermal growth factor receptor expression as a prognostic marker for breast cancer. Oncol Lett. 2018;15(6):9271-9282.

48. Nahta R, Yu D, Hung MC, Hortobagyi GN, Esteva FJ. Mechanisms of disease: understanding resistance to HER2-targeted therapy in human breast cancer. Nat Clin Pract Oncol. 2006;3(5):269-280.

49. Alawin OA, Ahmed RA, Ibrahim BA, Briski KP, Sylvester PW. Antiproliferative effects of $\gamma$-tocotrienol are associated with lipid raft disruption in HER2-positive human breast cancer cells. J Nutr Biochem. 2016;27:266-277.

50. Wang R, Li Z, Guo H, et al. Caveolin 1 knockdown inhibits the proliferation, migration and invasion of human breast cancer BT474 cells. Mol Med Rep. 2014;9(5):1723-1728.
51. Kang J, Park JH, Lee HJ, et al. Caveolin-1 modulates docetaxel-induced cell death in breast cancer cell subtypes through different mechanisms. Cancer Res Treat. 2016;48(2):715-726.

52. Xu F, Wang X, Wu N, et al. Bisphenol A induces proliferative effects on both breast cancer cells and vascular endothelial cells through a shared GPER-dependent pathway in hypoxia. Environ Pollut. 2017;231(Pt 2): 1609-1620.

53. Monti D, Sotgia F, Whitaker-Menezes D, et al. Pilot study demonstrating metabolic and anti-proliferative effects of in vivo anti-oxidant supplementation with $\mathrm{N}$-acetylcysteine in breast cancer. Semin Oncol. 2017;44(3):226-232.

54. Martins D, Beça FF, Sousa B, Baltazar F, Paredes J, Schmitt F. Loss of caveolin-1 and gain of MCT4 expression in the tumor stroma: key events in the progression from an in situ to an invasive breast carcinoma Cell Cycle. 2013;12(16):2684-2690.

55. Albanito L, Lappano R, Madeo A, et al. Effects of atrazine on estrogen receptor $\alpha$ - and $\mathrm{G}$ protein-coupled receptor 30-mediated signaling and proliferation in cancer cells and cancer-associated fibroblasts. Environ Health Perspect. 2015;123(5):493-499.

56. Liu J, Jin X, Zhao N, Ye X, Ying C. Bisphenol A promotes X-linked inhibitor of apoptosis protein-dependent angiogenesis via $\mathrm{G}$ proteincoupled estrogen receptor pathway. J Appl Toxicol. 2015;35(11): 1309-1317.

57. Castillo Sanchez R, Gomez R, Perez Salazar E. Bisphenol A induces migration through a GPER-, FAK-, Src-, and ERK2-dependent pathway in MDA-MB-231 breast cancer cells. Chem Res Toxicol. 2016;29(3): 285-295.

58. Semenza GL. The hypoxic tumor microenvironment: a driving force for breast cancer progression. Biochim Biophys Acta. 1863;2016(3): 382-391.

59. Shi XY, Xiong LX, Xiao L, et al. Downregulation of caveolin-1 upregulates the expression of growth factors and regulators in co-culture of fibroblasts with cancer cells. Mol Med Rep. 2016;13(1):744-752.

60. Li T, Kon N, Jiang L, et al. Tumor suppression in the absence of p53-mediated cell-cycle arrest, apoptosis, and senescence. Cell. 2012; 149(6):1269-1283.

61. Zhang L, Ren X, Alt E, et al. Chemoprevention of colorectal cancer by targeting APC-deficient cells for apoptosis. Nature. 2010;464(7291) 1058-1061.

62. Pfeffer CM, Singh ATK. Apoptosis: a target for anticancer therapy. Int J Mol Sci. 2018;19(2):E448.

63. Yu C, Li WB, Liu JB, Lu JW, Feng JF. Autophagy: novel applications of nonsteroidal anti-inflammatory drugs for primary cancer. Cancer Med. 2018;7(2):471-484.

64. Daskalaki I, Gkikas I, Tavernarakis N. Hypoxia and selective autophagy in cancer development and therapy. Front Cell Dev Biol. 2018;6:104.

65. Badana AK, Chintala M, Gavara MM, et al. Lipid rafts disruption induces apoptosis by attenuating expression of LRP6 and survivin in triple negative breast cancer. Biomed Pharmacother. 2018;97:359-368.

66. Wang R, He W, Li Z, Chang W, Xin Y, Huang T. Caveolin-1 functions as a key regulator of $17 \beta$-estradiol-mediated autophagy and apoptosis in BT474 breast cancer cells. Int J Mol Med. 2014;34(3):822-827.

67. Shi Y, Tan SH, Ng S, et al. Critical role of CAV1/caveolin-1 in cell stress responses in human breast cancer cells via modulation of lysosomal function and autophagy. Autophagy. 2015;11(5):769-784.

68. Salis O, Bedir A, Gulten S, Okuyucu A, Kulcu C, Alacam H. Cytotoxic effect of fluvastatin on MCF-7 cells possibly through a reduction of the mRNA expression levels of SGK1 and CaV1. Cancer Biother Radiopharm. 2014;29(9):368-375.

69. Salis O, Bedir A, Ozdemir T, Okuyucu A, Alacam H. The relationship between anticancer effect of metformin and the transcriptional regulation of certain genes (CHOP, Cav-1, HO-1, SGK-1 and PAR-4) on MCF-7 cell line. Eur Rev Med Pharmacol Sci. 2014;18(11):1602-1609.

70. Lee EJ, Yun UJ, Koo KH, et al. Down-regulation of lipid raft-associated onco-proteins via cholesterol-dependent lipid raft internalization in docosahexaenoic acid-induced apoptosis. Biochim Biophys Acta. 1841;2014(1):190-203. 
71. Goetz JG, Lajoie P, Wiseman SM, Nabi IR. Caveolin-1 in tumor progression: the good, the bad and the ugly. Cancer Metastasis Rev. 2008;27(4):715-735.

72. Bailey KM, Liu J. Caveolin-1 up-regulation during epithelial to mesenchymal transition is mediated by focal adhesion kinase. J Biol Chem. 2008;283(20):13714-13724.

73. Gai X, Lu Z, Tu K, Liang Z, Zheng X. Caveolin-1 is up-regulated by Gli1 and contributes to GLI1-driven EMT in hepatocellular carcinoma. PLoS One. 2014;9(1):e84551.

74. Lamouille S, Xu J, Derynck R. Molecular mechanisms of epithelialmesenchymal transition. Nat Rev Mol Cell Biol. 2014;15(3):178-196.

75. Cowin P, Welch DR. Breast cancer progression: controversies and consensus in the molecular mechanisms of metastasis and EMT. J Mammary Gland Biol Neoplasia. 2007;12(2-3):99-102.

76. Moreno-Bueno G, Portillo F, Cano A. Transcriptional regulation of cell polarity in EMT and cancer. Oncogene. 2008;27(55):6958-6969.

77. Huang H. Matrix metalloproteinase-9 (MMP-9) as a cancer biomarker and MMP-9 biosensors: recent advances. Sensors. 2018;18(10):3249.

78. Wang H, Zhu Y, Zhao M, et al. miRNA-29c suppresses lung cancer cell adhesion to extracellular matrix and metastasis by targeting integrin $\beta 1$ and matrix metalloproteinase2 (MMP2). PLoS One. 2013; 8(8):e70192.

79. Pal S, Ganguly KK, Chatterjee A. Extracellular matrix protein fibronectin induces matrix metalloproteinases in human prostate adenocarcinoma cells PC-3. Cell Commun Adhes. 2013;20(5):105-114.

80. Yao Q, Kou L, Tu Y, Zhu L. MMP-responsive "smart" drug delivery and tumor targeting. Trends Pharmacol Sci. 2018;39(8):766-781.

81. Zielinska HA, Holly JMP, Bahl A, Perks CM, Cm P, Bahl A. Inhibition of FASN and ER $\alpha$ signalling during hyperglycaemia-induced matrixspecific EMT promotes breast cancer cell invasion via a caveolin1-dependent mechanism. Cancer Lett. 2018;419:187-202.

82. Tsao SM, Hsu HY. Fucose-containing fraction of Ling-Zhi enhances lipid rafts-dependent ubiquitination of TGF $\beta$ receptor degradation and attenuates breast cancer tumorigenesis. Sci Rep. 2016;6:36563.

83. Gallardo M, Calaf GM. Curcumin and epithelial-mesenchymal transition in breast cancer cells transformed by low doses of radiation and estrogen. Int J Oncol. 2016;48(6):2534-2542.

84. Ponce-Cusi R, Calaf GM. Antitumor activity of pamidronate in breast cancer cells transformed by low doses of $\alpha$-particles and estrogen in vitro. Int J Oncol. 2015;46(6):2663-2669.

85. Cole GM, Lim GP, Yang F, et al. Prevention of Alzheimer's disease: omega-3 fatty acid and phenolic anti-oxidant interventions. Neurobiol Aging. 2005;26(Suppl 1):133-136.

86. Zheng W, Li J, Wang X, Yuan Y, Zhang J, Xiu Z. Effects of Antarctic krill docosahexaenoic acid on MCF-7 cell migration and invasion induced by the interaction of CD95 with caveolin-1. Life Sci. 2018;192: 270-277.

87. Braun AC, Olayioye MA. Rho regulation: DLC proteins in space and time. Cell Signal. 2015;27(8):1643-1651.

88. Joglekar M, Elbezanti WO, Weitzman MD, Lehman HL, van Golen KL. Caveolin-1 mediates inflammatory breast cancer cell invasion via the Akt1 pathway and RhoC GTPase. J Cell Biochem. 2015;116(6): 923-933.

89. Yang B, Zhu W, Zheng Z, et al. Fluctuation of ROS regulates proliferation and mediates inhibition of migration by reducing the interaction between DLC1 and Cav-1 in breast cancer cells. In Vitro Cell Dev Biol Anim. 2017;53(4):354-362.

90. Kandpal RP. Rho GTPase activating proteins in cancer phenotypes. Curr Protein Pept Sci. 2006;7(4):355-365.

91. Díaz J, Mendoza P, Ortiz R, et al. Rab5 is required in metastatic cancer cells for Caveolin-1-enhanced Rac1 activation, migration and invasion. J Cell Sci. 2014;127(Pt 11):2401-2406.

92. Kozyulina PY, Loskutov YV, Kozyreva VK, et al. Prometastatic NEDD9 regulates individual cell migration via caveolin-1-dependent trafficking of integrins. Mol Cancer Res. 2015;13(3):423-438.

93. Chen Y, Olopade OI. MYC in breast tumor progression. Expert Rev Anticancer Ther. 2008;8(10):1689-1698.
94. Xiong N, Li S, Tang K, et al. Involvement of caveolin-1 in low shear stress-induced breast cancer cell motility and adhesion: roles of FAK/ Src and ROCK/p-MLC pathways. Biochim Biophys Acta Mol Cell Res. 1864;2017(1):12-22.

95. Valastyan S, Weinberg RA. Tumor metastasis: molecular insights and evolving paradigms. Cell. 2011;147(2):275-292.

96. Chaffer CL, Weinberg RA. A perspective on cancer cell metastasis. Science. 2011;331(6024):1559-1564.

97. Gilmore AP. Anoikis. Cell Death Differ. 2005;12(Suppl 2):1473-1477.

98. Kim YN, Koo KH, Sung JY, Yun UJ, Kim H. Anoikis resistance: an essential prerequisite for tumor metastasis. Int J Cell Biol. 2012; 2012(4):1-11

99. Simpson CD, Anyiwe K, Schimmer AD. Anoikis resistance and tumor metastasis. Cancer Lett. 2008;272(2):177-185.

100. Paoli P, Giannoni E, Chiarugi P. Anoikis molecular pathways and its role in cancer progression. Biochim Biophys Acta. 1833;2013(12): 3481-3498.

101. Li S, Chen Y, Zhang Y, et al. Shear stress promotes anoikis resistance of cancer cells via caveolin-1-dependent extrinsic and intrinsic apoptotic pathways. J Cell Physiol. 2019;234(4):3730-3743.

102. Wang K, Zhu X, Chen Y, Yin Y, Ma T. Tubeimoside V sensitizes human triple negative breast cancer MDA-MB-231 cells to anoikis via regulating caveolin-1-related signaling pathways. Arch Biochem Biophys. 2018;646:10-15.

103. Nimri L, Barak H, Graeve L, Schwartz B. Restoration of caveolin-1 expression suppresses growth, membrane-type-4 metalloproteinase expression and metastasis-associated activities in colon cancer cells. Mol Carcinog. 2013;52(11):859-870.

104. Truong A, Yip C, Paye A, et al. Dynamics of internalization and recycling of the prometastatic membrane type 4 matrix metalloproteinase (MT4-MMP) in breast cancer cells. FEBS J. 2016;283(4): 704-722.

105. Celus W, di Conza G, Oliveira AI, et al. Loss of caveolin-1 in metastasis-associated macrophages drives lung metastatic growth through increased angiogenesis. Cell Rep. 2017;21(10):2842-2854.

106. Lv W, Chen N, Lin Y, et al. Macrophage migration inhibitory factor promotes breast cancer metastasis via activation of HMGB1/TLR4/ NF kappa B axis. Cancer Lett. 2016;375(2):245-255.

107. Alevizos L, Kataki A, Derventzi A, et al. Breast cancer nodal metastasis correlates with tumour and lymph node methylation profiles of caveolin-1 and CXCR4. Clin Exp Metastasis. 2014;31(5):511-520.

108. Kowalska K, Nowakowska M, Domińska K, Piastowska-Ciesielska AW. Coexpression of Cav-1, AT1-R and FoxM1 in prostate and breast cancer and normal cell lines and their influence on metastatic properties. Acta Biochim Pol. 2016;63(3):493-499.

109. Magbanua MJM, Rugo HS, Hauranieh L, et al. Genomic and expression profiling reveal molecular heterogeneity of disseminated tumor cells in bone marrow of early breast cancer. NPJ Breast Cancer. 2018; 4(1):31.

110. Kuczynski EA, Sargent DJ, Grothey A, Kerbel RS. Drug rechallenge and treatment beyond progression - implications for drug resistance. Nat Rev Clin Oncol. 2013;10(10):571-587.

111. Mallini P, Lennard T, Kirby J, Meeson A. Epithelial-to-mesenchymal transition: what is the impact on breast cancer stem cells and drug resistance. Cancer Treat Rev. 2014;40(3):341-348.

112. Hehlgans S, Cordes N. Caveolin-1: an essential modulator of cancer cell radio-and chemoresistance. Am J Cancer Res. 2011;1(4):521-530.

113. Wang Z, Liu P, Chen Q, et al. Targeting AMPK signaling pathway to overcome drug resistance for cancer therapy. Curr Drug Targets. 2016;17(8):853-864.

114. Wang Z, Wang N, Li W, et al. Caveolin-1 mediates chemoresistance in breast cancer stem cells via $\beta$-catenin/ABCG2 signaling pathway. Carcinogenesis. 2014;35(10):2346-2356.

115. Herzog M, Storch CH, Gut P, et al. Knockdown of caveolin-1 decreases activity of breast cancer resistance protein (BCRP/ABCG2) and increases chemotherapeutic sensitivity. Naunyn Schmiedebergs Arch Pharmacol. 2011;383(1):1-11. 
116. Peng L, Chen X. Antibody-drug conjugates. Bioconjug Chem. 2015; 26(11):2169.

117. Kim EG, Kim KM. Strategies and advancement in antibody-drug conjugate optimization for targeted cancer therapeutics. Biomol Ther. 2015;23(6):493-509.

118. Lorusso PM, Weiss D, Guardino E, Girish S, Sliwkowski MX. Trastuzumab emtansine: a unique antibody-drug conjugate in development for human epidermal growth factor receptor 2-positive cancer. Clin Cancer Res. 2011;17(20):6437-6447.

119. Sekhar SC, Kasai T, Satoh A, et al. Identification of caveolin-1 as a potential causative factor in the generation of trastuzumab resistance in breast cancer cells. J Cancer. 2013;4(5):391-401.

120. Chung YC, Kuo JF, Wei WC, Chang KJ, Chao WT. Caveolin-1 dependent endocytosis enhances the chemosensitivity of HER-2 positive breast cancer cells to trastuzumab emtansine (T-DM1). PLoS One. 2015;10(7):e0133072.

121. Chung YC, Chang CM, Wei WC, Chang TW, Chang KJ, Chao WT. Metformin-induced caveolin-1 expression promotes T-DM1 drug efficacy in breast cancer cells. Sci Rep. 2018;8(1):3930.

122. von der Heyde S, Wagner S, Czerny A, et al. mRNA profiling reveals determinants of trastuzumab efficiency in HER2-positive breast cancer. PLoS One. 2015;10(2):e0117818.

123. Sung M, Tan X, Lu B, et al. Caveolae-mediated endocytosis as a novel mechanism of resistance to trastuzumab emtansine (T-DM1) Mol Cancer Ther. 2018;17(1):243-253.

124. Zheng Y, Dai Y, Liu W, et al. Astragaloside IV enhances taxol chemosensitivity of breast cancer via caveolin-1-targeting oxidant damage. J Cell Physiol. 2019;234(4):4277-4290.

125. Li Z, Yang SS, Yin PH, et al. Activated estrogen receptor-mitogenactivated protein kinases cross talk confer acquired resistance to lapatinib. Thoracic Cancer. 2015;6(6):695-703.

126. Zou M, Li Y, Xia S, et al. Knockdown of caveolin-1 sensitizes human basal-like triple-negative breast cancer cells to radiation. Cell Physiol Biochem. 2017;44(2):778-791

127. Malik B, Nie D. Cancer stem cells and resistance to chemo and radio therapy. Front Biosci. 2012;4:2142-2149.

128. Szakács G, Paterson JK, Ludwig JA, Booth-Genthe C, Gottesman MM. Targeting multidrug resistance in cancer. Nat Rev Drug Discov. 2006; 5(3):219-234.

129. Trumpp A, Wiestler OD. Mechanisms of disease: cancer stem cells targeting the evil twin. Nat Clin Pract Oncol. 2008;5(6):337-347.

130. Maugeri-Saccà M, Vigneri $\mathrm{P}$, de Maria R. Cancer stem cells and chemosensitivity. Clin Cancer Res. 2011;17(15):4942-4947.

131. Dean M. ABC transporters, drug resistance, and cancer stem cells. J Mammary Gland Biol Neoplasia. 2009;14(1):3-9.

132. Donnenberg VS, Meyer EM, Donnenberg AD. Measurement of multiple drug resistance transporter activity in putative cancer stem/ progenitor cells. Methods Mol Biol. 2009;568:261-279.

133. Hirsch HA, Iliopoulos D, Tsichlis PN, Struhl K. Metformin selectively targets cancer stem cells, and acts together with chemotherapy to block tumor growth and prolong remission. Cancer Res. 2009;69(19): 7507-7511.

134. Marie-Egyptienne DT, Lohse I, Hill RP. Cancer stem cells, the epithelial to mesenchymal transition (EMT) and radioresistance: potential role of hypoxia. Cancer Lett. 2013;341(1):63-72.

135. Merlos-Suárez A, Barriga FM, Jung P, et al. The intestinal stem cell signature identifies colorectal cancer stem cells and predicts disease relapse. Cell Stem Cell. 2011;8(5):511-524.

136. Perona R, López-Ayllón BD, de Castro Carpeño J, Belda-Iniesta C. A role for cancer stem cells in drug resistance and metastasis in nonsmall-cell lung cancer. Clin Transl Oncol. 2011;13(5):289-293.

137. Sheridan C, Kishimoto H, Fuchs RK, et al. CD44+/CD24- breast cancer cells exhibit enhanced invasive properties: an early step necessary for metastasis. Breast Cancer Res. 2006;8(5):R59.

138. Yuan G, Regel I, Lian F, et al. WNT6 is a novel target gene of caveolin-1 promoting chemoresistance to epirubicin in human gastric cancer cells. Oncogene. 2013;32(3):375-387.
139. Yongsanguanchai N, Pongrakhananon V, Mutirangura A, Rojanasakul Y, Chanvorachote P. Nitric oxide induces cancer stem cell-like phenotypes in human lung cancer cells. Am J Physiol Cell Physiol. 2015;308(2):C89-C100.

140. Eliyatkin N, Aktas S, Diniz G, Ozgur HH, Ekin ZY, Kupelioglu A. Expression of stromal caveolin-1 may be a predictor for aggressive behaviour of breast cancer. Pathol Oncol Res. 2018;24(1):59-65.

141. Pucci M, Bravatà V, Forte GI, et al. Caveolin-1, breast cancer and ionizing radiation. Cancer Genomics Proteomics. 2015;12(3): 143-152.

142. Witkiewicz AK, Dasgupta A, Nguyen KH, et al. Stromal caveolin-1 levels predict early DCIS progression to invasive breast cancer. Cancer Biol Ther. 2009;8(11):1071-1079.

143. Sotgia F, Martinez-Outschoorn UE, Howell A, Pestell RG, Pavlides S, Lisanti MP. Caveolin-1 and cancer metabolism in the tumor microenvironment: markers, models, and mechanisms. Annu Rev Pathol. 2012; $7(1): 423-467$.

144. Yeong J, Thike AA, Ikeda M, et al. Caveolin-1 expression as a prognostic marker in triple negative breast cancers of Asian women. J Clin Pathol. 2018;71(2):161-167.

145. Li X, Sun J, Hu S. Expression of caveolin-1 in breast cancer stroma as a potential prognostic biomarker of survival and progression: a meta-analysis. Wien Klin Wochenschr. 2017;129(15-16):558-563.

146. Ma X, Liu L, Nie W, et al. Prognostic role of caveolin in breast cancer: a meta-analysis. Breast. 2013;22(4):462-469.

147. Elsheikh SE, Green AR, Rakha EA, et al. Caveolin 1 and caveolin 2 are associated with breast cancer basal-like and triple-negative immunophenotype. Br J Cancer. 2008;99(2):327-334.

148. Qian N, Ueno T, Kawaguchi-Sakita N, et al. Prognostic significance of tumor/stromal caveolin-1 expression in breast cancer patients. Cancer Sci. 2011;102(8):1590-1596.

149. Jensen DH, Therkildsen MH, Dabelsteen E. A reverse Warburg metabolism in oral squamous cell carcinoma is not dependent upon myofibroblasts. J Oral Pathol Med. 2015;44(9):714-721.

150. Tasdemir N, Bossart EA, Li Z, et al. Comprehensive phenotypic characterization of human invasive lobular carcinoma cell lines in 2D and 3D cultures. Cancer Res. 2018;78(21):6209-6222.

151. Fard ZT, Nafisi N. The relationship between 6 polymorphisms of caveolin-1 gene and the risk of breast cancer. Clin Breast Cancer. 2018;18(5):e893-e898.

152. Deb M, Sengupta D, Kar S, et al. Elucidation of caveolin 1 both as a tumor suppressor and metastasis promoter in light of epigenetic modulators. Tumour Biol. 2014;35(12):12031-12047.

153. Chanvorachote $\mathrm{P}$, Chunhacha P. Caveolin-1 regulates endothelial adhesion of lung cancer cells via reactive oxygen species-dependent mechanism. PLoS One. 2013;8(2):e57466.

154. Wu J, di D, Zhao C, et al. Clinical significance of Gli-1 and caveolin-1 expression in the human small cell lung cancer. Asian Pac J Cancer Prev. 2018;19(2):401-406.

155. Zhao Z, Han FH, Yang SB, Hua LX, Jh W, Zhan WH. Loss of stromal caveolin-1 expression in colorectal cancer predicts poor survival. World J Gastroenterol. 2015;21(4):1140-1147.

156. Wang Y, Song Y, Che X, et al. Caveolin-1 enhances RANKL-induced gastric cancer cell migration. Oncol Rep. 2018;40(3):1287-1296.

157. Liang X, Chen W, Shi H, et al. PTBP3 contributes to the metastasis of gastric cancer by mediating CaV1 alternative splicing. Cell Death Dis. 2018;9(5):569.

158. Zhang T, Wang T, Cai P. Sclareol inhibits cell proliferation and sensitizes cells to the antiproliferative effect of bortezomib via upregulating the tumor suppressor caveolin-1 in cervical cancer cells. Mol Med Rep. 2017;15(6):3566-3574.

159. Takeda M, Sakaguchi T, Hiraide T, et al. Role of caveolin-1 in hepatocellular carcinoma arising from non-alcoholic fatty liver disease. Cancer Sci. 2018;109(8):2401-2411.

160. Demirci NS, Dogan M, Erdem GU, et al. Is plasma caveolin-1 level a prognostic biomarker in metastatic pancreatic cancer? Saudi J Gastroenterol. 2017;23(3):183-189. 
161. Zhou W, He L, Dai Y, Zhang Y, Wang J, Liu B. MicroRNA-124 inhibits cell proliferation, invasion and migration by targeting CaV1 in bladder cancer. Exp Ther Med. 2018;16(4):2811-2820.

162. Garcia-Rivas G, Jerjes-Sánchez C, Rodriguez D, Garcia-Pelaez J, Trevino V. A systematic review of genetic mutations in pulmonary arterial hypertension. BMC Med Genet. 2017;18(1):82.

163. Kobayashi H, Kabata R, Kinoshita H, et al. Rare variants in RNF213, a susceptibility gene for moyamoya disease, are found in patients with pulmonary hypertension and aggravate hypoxia-induced pulmonary hypertension in mice. Pulm Circ. 2018;8(3):204589401877815.

164. Girerd B, Lau E, Montani D, Humbert M. Genetics of pulmonary hypertension in the clinic. Curr Opin Pulm Med. 2017;23(5):386-391.

165. Mahdy MM, El-Ekiaby NM, Hashish RM, et al. miR-29a promotes lipid droplet and triglyceride formation in HCV infection by inducing expression of SREBP-1c and CaV1. J Clin Transl Hepatol. 2016; 4(4):293-299.

166. Somrit M, Watthammawut A, Chotwiwatthanakun C, Weerachatyanukul W. The key molecular events during Macrobrachium rosenbergii nodavirus (MrNV) infection and replication in $\mathrm{Sf9}$ insect cells. Virus Res. 2016;223:1-9.
167. Hu Z, Liang M, Soong T. Alternative splicing of L-type Cav1.2 calcium channels: implications in cardiovascular diseases. Genes. 2017; 8(12):344.

168. Chen S, Wang X, Wang J, et al. Genomic variant in CaV1 increases susceptibility to coronary artery disease and myocardial infarction. Atherosclerosis. 2016;246:148-156.

169. Torella D, Iaconetti C, Tarallo R, et al. miRNA regulation of the hyperproliferative phenotype of vascular smooth muscle cells in diabetes. Diabetes. 2018;67(12):2554-2568.

170. Xiang S, Sarem M, Shah S, Shastri VP. Liposomal treatment of cancer cells modulates uptake pathway of polymeric nanoparticles by altering membrane stiffness. Small. 2018;14(14):e1704245.

171. Han B, Copeland CA, Kawano Y, et al. Characterization of a caveolin-1 mutation associated with both pulmonary arterial hypertension and congenital generalized lipodystrophy. Traffic. 2016;17(12):1297-1312.

172. Badana A, Chintala M, Varikuti G, et al. Lipid raft integrity is required for survival of triple negative breast cancer cells. J Breast Cancer. 2016;19(4):372-384.
OncoTargets and Therapy

\section{Publish your work in this journal}

OncoTargets and Therapy is an international, peer-reviewed, open access journal focusing on the pathological basis of all cancers, potential targets for therapy and treatment protocols employed to improve the management of cancer patients. The journal also focuses on the impact of management programs and new therapeutic agents and protocols on

\section{Dovepress}

patient perspectives such as quality of life, adherence and satisfaction. The manuscript management system is completely online and includes a very quick and fair peer-review system, which is all easy to use. Visit http://www.dovepress.com/testimonials.php to read real quotes from published authors. 